\title{
Model Pemrograman Tujuan Untuk Pengambilan Keputusan Pemeliharaan Komponen Kritis Mesin Dengan Pertimbangan Multi Kriteria
}

\author{
Taufiq Aji dan Septa Praditya \\ Program Studi Teknik industri, Fakultas Sains dan Teknologi, UIN Sunan Kalijaga, JI. Marsda \\ Adisucipto No. 1 Yogyakarta, Indonesia \\ Korespondensi; Taufiq Aji, Email: ajiq15@yahoo.com; SeptaPraditya, Email: this_isepta@yahoo.com
}

\begin{abstract}
Abstrak
Makalah ini menjelaskan tentang pengambilan keputusan pemeliharaan komponen kritis dengan menggunakan pendekatan Multi Kriteria. Mesin yang diteliti untuk dilakukan pemeliharaan adalah mesin Kompresor pada proses penenunan di PT. X. Adapun metode yang digunakan pada penelitian adalah metode Analythical Hierarchy Procces (AHP) dan metode Goal Programming (GP). Kriteria yang terdapat pada tahap metode AHP menggunakan metode Failure Mode Effect Analysis(FMEA) yaitu berdasarkan Occurence, Severity, dan Detectability. Sedangkan untuk alternatif keputusan program pemeliharaan adalah Bersihkan, Cek, Perbaiki, dan Ganti. Jenis komponen kritis yang ada pada mesin kompresor berjumlah 5 komponen yaitu, Air Intake, Filter HAF \& HMF, Oli Mesin, Air End, dan Oil Separator. Hasil yang didapatkan pada penelitian ini adalah keputusan untuk program pemeliharaan pada mesin kompresor adalah, untuk komponen Air Intake diputuskan program pemeliharaan Bersihkan, Cek, dan Ganti. Komponen Filter HAF \& HMF diputuskan program pemeliharaan Cek dan Ganti. Untuk komponen Oli Mesin diputuskan program pemeliharaan Cek dan Ganti. Komponen Air End diputuskan program pemeliharaan Cek, Ganti, dan Perbaiki. Sedangkan untuk Komponen Oil Separator diputuskan program pemeliharaan Bersihkan, Cek, dan Ganti. Pertimbangan dalam pengambilan keputusan diambil berdasarkan faktor besarnya biaya pada tiap komponen kritis.
\end{abstract}

Kata Kunci: Pemeliharaan; Multi Criteria; Analytical Hierarchy Process; FMEA; Goal Programming

\begin{abstract}
This paper describes critical component maintenance decisions using the Multi Criteria approach. The machine under study for maintenance is a compressor machine on the weaving process at PT. X. The method used in this research is Analythical Hierarchy Procces (AHP) and Goal Programming (GP) method. The criteria contained in the AHP method stage using Failure Mode Effect Analysis (FMEA) method is based on Occurrence, Severity, and Detectability. As for alternative maintenance program decisions are Clean, Check, Repair, and Replace. The critical component types in the compressor engine are 5 components, Air Intake, HAF \& HMF Filter, Engine Oil, Air End, and Oil Separator. The results obtained in this study is the decision to program maintenance on the compressor engine is, for the Air Intake component was decided Clean maintenance program, Checks, and Replace. The HAF \& HMF Filter Component is decided on the Check and Replace maintenance program. For the Engine Oil component is decided the Check and Replace maintenance program. Air End Component is decided maintenance program Check, Replace, and Fix. As for the Oil Separator Components, the Cleaning, Check and Replace maintenance program is decided. Consideration in decision making is taken based on the factor of cost in each critical component.
\end{abstract}

Keywords: Maintenance; Multi Criteria; Analytical Hierarchy Process; FMEA; Goal Programming

\section{Pendahuluan}

Produktifitas mesin pabrik menuntut adanya sistem pemeliharaan mesin secara optimal. Pencapaian optimalitas pemeliharaan mesin mempertimbangkan beberapa faktor kunci seperti seberapa sering 
mesin mengalami kerusakan, seberapa serius biasanya mesin mengalami gangguan, dan apakah terdapat mekanisme yang mampu mendeteksi adanya kerusakan mesin sejak awal. Dalam hal ini faktor-faktor tersebut merupakan konsep dasar analisis efek kegagagalan atau dikenal sebagai Failure Mode Effect Analysis (FMEA), terdiri atas Occurence, Severity, dan Detection.

Salah satu jenis industri yang membutuhkan penanganan perawatan serius adalah industri tekstil dimana jenis industri ini biasanya bekerja selama 24 jam 7 hari seminggu selama setahun dengan beberapa hari dilakukan overhaul untuk menangani kerusakan dan gangguan pada mesin. Setiap saat dikehendaki mesin dapat berada dalam kondisi prima terutama pada mesin-mesin yang dianggap kritis. Salah satu mesin yang dianggap kritis dalam industri ini adalah mesin yang melayani kinerja mesin lainnya, sebagai contoh adalah mesin kompresor. Mesin ini memasok udara bertekanan kepada setiap mesin yang bekerja memintal benang atau menenun kain.

Mesin-mesin dengan tipikal seperti halnya kompresor di atas diharapkan selalu terjaga kondisinya dalam keadaan prima, menuntut adanya kegiatan perawatan prefentif. Perusahaan PT. X sebagai pemasok produk tekstil memiliki departemen penenunan (weaving) terdiri atas sejumlah mesin pintal yang disusun membentuk line produksi dengan pendukung berupa satu buah mesin kompresor kapasitas besar. Sekali kompresor mengalami kerusakan maka, rangkaian produksi akan terhenti dan mengakibatkan kerugian (production lost) akibat tidak berjalannya produksi. Maka dari itu mesin kompresor merupakan mesin yang memiliki agenda pemeliharaan prefentif secara ketat. Namun demikian, perawatan preventif yang berlebihan juga akan mengakibatkan tingginya biaya pemeliharaan. Oleh karena itu harus dibuat suatu formulasi pemeliharaan preventif yang merupakan jalan tengah (trade-off) antara mengetatkan pemeliharaan atau terjadi production lost.

Penelitian ini mengembangkan model pemeliharaan preventif dengan menggunakan teknik pemrograman tujuan (goal programming) berdasarkan pertimbangan keputusan multikriteria. Terminologi multikriteria mengacu pada teknik Multi Attribute Decision Making MADM dengan menggunakan metode Analytical Hierarchy Process (AHP). Hasil pengembangan model diujicoba menggunakan data perusahaan untuk menghasilkan formulasi penanganan perawatan preventif.

\section{Failure Mode Effect Analysis (FMEA)}

FMEA adalah suatu metode sistematis yang membantu dalam mengidentifikasi cacat dan serta mencegah kegagalan potensial atas produk atau proses sebelum terjadi. FMEA dapat dipandang sebagai salah satu bagian integral sistem kualitas total pada sebuah perusahaan atau bagian dari perusahaan. Gagasan inti metode FMEA adalah dengan mendapatkan suatu ukuran resiko kegagalan dinamakan Risk Priority Number (RPN). Semakin tinggi nilai RPN maka resiko suatu sistem produk atau proses untuk gagal akan semakin tinggi.

Nilai RPN pada FMEA ditentukan oleh tiga hal yaitu Occurence, Severity, dan Detection dijelakan sebagai berikut:

1. Occurrence, merupakan skala seberapa sering kegagalan akan muncul berdasarkan data historis

2. Severity, merupakan skala yang memeringkat seberapa serius dampak yang timbul manakala terjadi kegagalan pada sistem.

3. Detection, merupakan skala yang memeringkat kemungkinan dari masalah akan dapat terdeteksi.

Dalam kaitan dengan sistem pemeliharaan FMEA telah digunakan untuk membantu merencanakan aktivitas perawatan pada mesin-mesin produksi (Bertolini \& Bevilacqua, 2006). Penelitian tersebut membahas tentang bagaimana memilih alternatif program pemeliharaan antara pemeliharaan preventif dan korektif.

\section{Kerangka Keputusan Pemrograman Tujuan-AHP}

Pemrograman Tujuan (Goal Programming) adalah salah satu jenis pemrograman linear untuk menentukan nilai target spesifik atas suatu objek dengan melibatkan sejumlah kendala (contraints) tertentu. Ide dasarnya adalah bagaimana meminimalkan jumlah deviasi terhadap nilai target yang 
ditetapkan (Hiller \& Lieberman, 2001). Terdapat dua macam kendala, yaitu pembatas ekonomis dan pembatas tujuan. Pembatas Ekonomis adalah pembatas yang berkaitan dengan batasan fisik, ketersediaan sumberdaya, dan keuangan. Pembatas tujuan adalah pembatas yang berkaitan dengan pemenuhan target tujuan. Persamaan pembatas tujuan melibatkan variabel deviasi, $d_{k}^{+}$dan $d_{k}^{-}$yang menggambarkan penyimpangan (gap) terhadap target.

Sementara itu, metode AHP merupakan salah satu metode pengambilan keputusan multi kriteria dimana model keputusannya disusun dalam bentuk hierarki. Prinsip kerja dasar AHP adalah menyederhanakan masalah kompleks yang tidak terstruktur, strategik dan dinamik dengan menata variabel dalam suatu hirarki (tingkatan). Langkah-langkah metode AHP dapat dijelaskan sebagai berikut:

a. Menyusun daftar penilaian dari hirarki permasalahan dalam bentuk pairwise comparison.

b. Menghitung bobot prioritas hirarki

c. Menghitung indeks konsistensi

Langkah-langkahnya adalah:

1. Eigen vektor. mengalikan setiap elemen baris dari matriks asal dengan bobot prioritas dan menjumlahkan setiap barisnya.

2. Eigen value: membagi hasil langkah 1 dengan bobot prioritas.

3. Menghitung harga rata-rata sebagai nilai eigen value terbesar $(\lambda \max )$.

4. Indeks konsistensinya adalah:

$$
C I=\frac{\lambda \max -N}{N-1}
$$

5. Menghitung rasio konsistensi

$$
C R=\frac{C I}{R I}
$$

6. Membuat matriks nilai perbandingan hasil normalisasi dengan menggunakan rumus Geometric Mean tersebut adalah:

$$
G M=\left(x_{1}, x_{2}, x_{3}, \cdots x_{n}\right)^{1 / n}
$$

Pada penelitian ini, metode AHP digunakan untuk menentukan skor masing-masing iternatif program pemeliharaan preventif terdiri atas:

- bersihkan: membersihkan bagian komponen sehingga kinerja mesin lancar

- cek: mengecek kondisi mesin dengan membuka selubung mesin dan bagian-bagian tertentu.

- ganti: mengganti sparepart

- perbaiki: membongkar mesin untuk disetel kembali

Masing-masing _Iternative diberikan skor berdasarkan tiga pertimbangan berdasarkan FMEA yaitu Occurrence, Severity, dan Detection, diilustrasikan oleh gambar berikut:

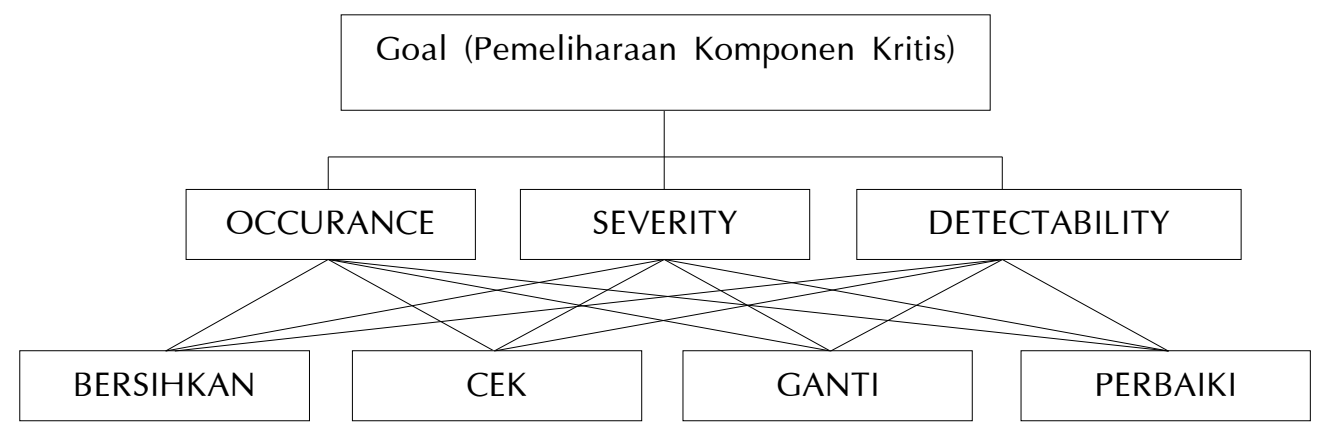

Gambar 1 Hirarki AHP. 
Pada setiap level hirarki, skor yang didapat dari metode AHP akan digunakan untuk perhitungan dalam model pemrograman tujuan. Berikut ini adalah kerangka model penyelesaian gabungan metode Pemrograman Tujuan AHP:

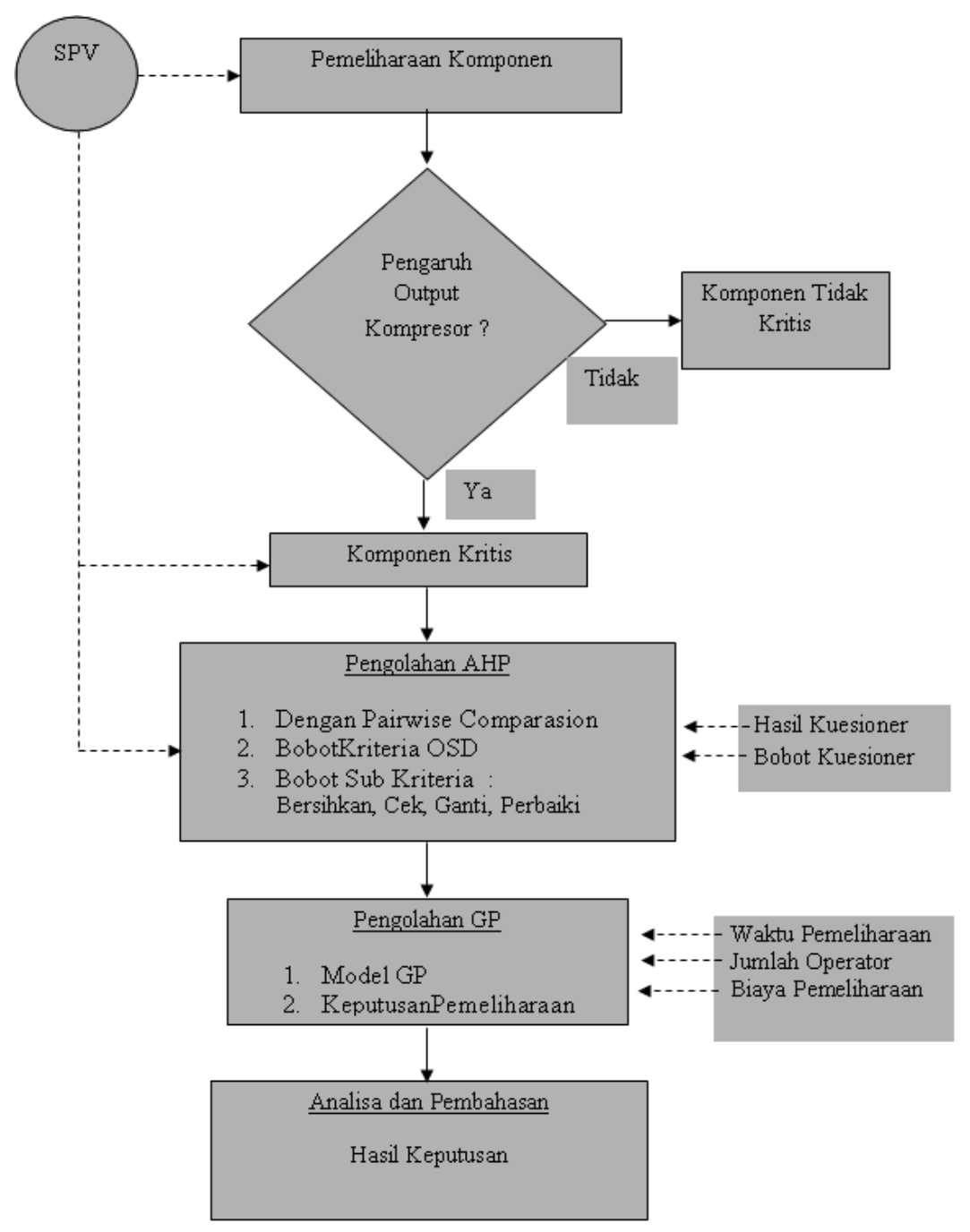

Gambar 2 Kerangka Pengambilan Keputusan Pemeliharaan.

\section{Model Matematika Pemrograman Tujuan - AHP}

Berdasarkan gambaran permasalahan dan kerangka keputusan di atas, selanjutnya dirumuskan model matematika menggunakan model pemrograman tujuan dengan menggunakan hasil perhitungan skor AHP pada setiap level.

\section{Notasi Indeks}

$i$ : Indeks jenis pemeliharaan, $k=\{$ Corrective, Preventive, Conditional\}

$j:$ Indeks program pemeliharaan. $j=\{$ Bersihkan, Cek, Ganti, Perbaik $\}$

$k$ : Indeks komponen kritis. $k=\{1,2,3, \ldots ., K\}$

\section{Notasi Parameter}

$T_{O} \quad$ : Target skor Occurence.

$T_{S} \quad$ : Target skor Severity.

$T_{D} \quad$ : Target skor Detectability. 
$T_{A H P} \quad:$ Target skor AHP.

$T_{C} \quad$ : Target skor biaya.

$O_{i k} \quad:$ Skor Occurence jenis pemeliharaan $i$ dan komponen kritis $k$.

$O_{j k} \quad$ : Skor Occurence program pemeliharaan $j$ dan komponen $k$.

$S_{i k} \quad:$ Skor Severity jenis pemeliharaan $i$ dan komponen kritis $k$.

$S_{j k} \quad:$ Skor Severity program pemeliharaan $j$ dan komponen kritis $k$.

$D_{i k} \quad: \quad$ Skor Detectability jenis pemeliharaan $i$ dan komponen kritis $k$.

$D_{j k} \quad$ : Skor Detectability program pemeliharaan $j$ dan komponen kritis $k$.

$A H P_{i k}:$ Skor AHP jenis pemeliharaan $i$ dan komponen kritis $k$.

$A H P_{j k}$ : Skor AHP program pemeliharaan $j$ dan komponen kritis $k$.

$C_{i} \quad:$ Skor biaya jenis pemeliharaan $i$ dan komponen kritis $k$.

$C_{j k}:$ Skor biaya program pemeliharaan $j$ dan komponen kritis $k$.

\section{Notasi Variabel}

$X_{i k}:$ Alternatif jenis pemeliharaan dan komponen yang bernilai biner.

$X_{j k}:$ Alternatif program pemeliharaan dan komponen yang bernilai biner.

$d_{O k}^{-} \quad$ : Deviasi negatif Occurence komponen $k$ dari nilai batasan yang telah ditentukan.

$d_{O K} \quad:$ Deviasi positif Occurence komponen $k$ dari nilai batasan yang telah ditentukan.

$d_{S k}^{-} \quad:$ Deviasi negatif Severity komponen $k$ dari nilai batasan yang telah ditentukan.

$d_{S k}^{+} \quad:$ Deviasi positif Severity komponen $k$ dari nilai batasan yang telah ditentukan.

$d_{D k}^{-} \quad$ : Deviasi negatif Detectability komponen $k$ dari nilai batasan yang telah ditentukan.

$d_{D k}^{+} \quad$ : Deviasi positif Detectability komponen $k$ dari nilai batasan yang telah ditentukan.

$d_{A H P k}^{-} \quad:$ Deviasi negatif AHP komponen $k$ dari nilai batasan yang telah ditentukan.

$d_{A H P k}^{+}:$Deviasi positif AHP komponen $k$ dari nilai batasan yang telah ditentukan.

$d_{C k}^{-} \quad$ : Deviasi negatif biaya komponen $k$ dari nilai batasan yang telah ditentukan.

$d_{C k}^{+} \quad$ : Deviasi positif biaya komponen $k$ dari nilai batasan yang telah ditentukan.

\section{Fungsi Tujuan:}

$$
\text { Min Deviasi }=P_{1}\left(d_{c k}^{+}\right)+P_{2}\left(d_{A H P k}^{-}\right)+P_{3}\left(w_{O} d_{O}^{-}+w_{S} d_{S}^{-}+w_{D} d_{D}^{-}\right)
$$

Batasan biaya pemeliharaan:

\section{Batasan Score AHP:}

$$
\sum_{j=1}^{l}\left(\sum_{k=1}^{n} A H P_{j k} \cdot x_{j k}+d_{c k}^{-}+d_{c k}^{+}\right)=T_{c}
$$

$$
\sum_{j=1}^{l}\left(\sum_{k=1}^{n} A H P_{j k} \cdot x_{j k}+d_{A H P k}^{-}+d_{A H P k}^{+}\right)=1
$$

Batasan Score OSD:
a. Occurence

$$
\sum_{j=1}^{l}\left(\sum_{k=1}^{n} \operatorname{SCORE} O_{j k} \cdot x_{j k}+d_{O k}^{-}+d_{O k}^{+}\right)=T_{O}
$$

b. Severity

$$
\sum_{j=1}^{l}\left(\sum_{k=1}^{n} \operatorname{SCORES} S_{j k} \cdot x_{j k}+d_{S k}^{-}+d_{S k}^{+}\right)=T_{S}
$$

c. Detectability

$$
\sum_{j=1}^{l}\left(\sum_{k=1}^{n} \operatorname{SCORE} D_{j k} \cdot x_{j k}+d_{D k}^{-}+d_{D k}^{+}\right)=T_{D}
$$




\section{Penjumlahan Biner:}

$$
X_{j k}+X_{j k}+X_{j k}+X_{j k} \geq 1, \quad \forall k=1,2,3, \ldots, K
$$

\section{Studi Kasus}

Dalam pemilihan sistem pemeliharaan di PT. X, membagi menjadi empat jenis alternatif program pemeliharaan komponen kritis, yaitu Bersihkan, Cek, Perbaiki, dan Ganti. Program pemeliharaan tesebut ditentukan berdasarkan diskusi dengan bagian pemeliharaan mesin. Sedangkan kriteria pada hirarki permasalahan yang dituju adalah beberapa kriteria dari metode FMEA yang diadaptasikan ke dalam metode AHP, kriteria tersebut yaitu Occurence, Saverity, dan Detectability.

Berdasarkan penilaian bagian pemeliharaan, terdapat lima (5) macam komponen kritis pada mesi kompresor yaitu Air Intake, Filter HAF \& HMF, Oli Mesin, Air End (Services), dan Oil Filter. Masingmasing komponen tersebut membutuhkan sejumlah biaya pemeliharaan untuk masing-masing program pemeliharaan. Untuk memudahkan proses penghitungan pada model, maka besaran biaya tersebut diubah menjadi tidak bersatuan dengan melakukan normalisasi, didapatkan hasil skor biaya. Sementara untuk skor-AHP dilakukan dengan metode AHP untuk mendapatkan skor-AHP serta skor Occurence, Severity dan Detection untuk masing-masing program pemeliharaan pada tiap-tiap komponen. Hasil lengkapnya diberikan data sebagai berikut.

Tabel 1 Score harga pemeliharaan.

\begin{tabular}{l|l|llll}
\hline & 1 & 0.035 & 0.138 & 0.276 & 0.551 \\
& 2 & 0.286 & 0.143 & 0.286 & 0.286 \\
Cost & 3 & 0.376 & 0.059 & 0.376 & 0.188 \\
& 4 & 0.286 & 0.286 & 0.286 & 0.143 \\
& 5 & 0.006 & 0.142 & 0.284 & 0.568 \\
\hline
\end{tabular}

Tabel 2 Score AHP.

\begin{tabular}{l|l|llll}
\hline & 1 & 0.252 & 0.218 & 0.318 & 0.212 \\
& 2 & 0.075 & 0.199 & 0.509 & 0.216 \\
AHP & 3 & 0.080 & 0.325 & 0.443 & 0.152 \\
& 4 & 0.068 & 0.318 & 0.423 & 0.191 \\
& 5 & 0.331 & 0.215 & 0.325 & 0.129 \\
\hline
\end{tabular}

Tabel 3 Score O.

\begin{tabular}{l|l|llll}
\hline & 1 & 0.365 & 0.402 & 0.388 & 0.142 \\
Occurence & 2 & 0.413 & 0.322 & 0.383 & 0.198 \\
& 3 & 0.328 & 0.445 & 0.248 & 0.345 \\
& 4 & 0.374 & 0.451 & 0.255 & 0.296 \\
& 5 & 0.458 & 0.243 & 0.311 & 0.220 \\
\hline
\end{tabular}

Tabel 4 Score S.

\begin{tabular}{l|l|llll}
\hline \multirow{5}{*}{ Severity } & 1 & 0.194 & 0.087 & 0.496 & 0.510 \\
& 2 & 0.272 & 0.166 & 0.387 & 0.382 \\
& 3 & 0.204 & 0.128 & 0.518 & 0.304 \\
& 4 & 0.221 & 0.089 & 0.479 & 0.456 \\
& 5 & 0.265 & 0.247 & 0.513 & 0.199 \\
\hline
\end{tabular}

Tabel 5 Score D.

\begin{tabular}{l|l|llll}
\hline & 1 & 0.441 & 0.511 & 0.116 & 0.349 \\
& 2 & 0.314 & 0.512 & 0.229 & 0.420 \\
Detectability & 3 & 0.468 & 0.427 & 0.234 & 0.351 \\
& 4 & 0.406 & 0.459 & 0.265 & 0.248 \\
& 5 & 0.278 & 0.509 & 0.176 & 0.581 \\
\hline
\end{tabular}


Data-data di atas kemudian dimasukkan pada model pemrograman tujuan yang ditulis ulang ke dalam aplikasi spreadsheet Microsoft Excel dengan addins Solver. Hasil menjalankan aplikasi ditampilkan dalam format bilangan biner dimana nilai 1 menyatakan bahwa komponen dilakukan suatu pemeliharaan, sedangkan nilai 0 tidak dilakukan program pemeliharaan. Hasil keputusan sebagai tabel berikut:

Tabel 6 Keputusan pemeliharaan.

\begin{tabular}{c|c|c|c|c}
\hline No & Bersihkan & Cek & Ganti & Perbaiki \\
\hline 1 & 1 & 1 & 1 & 0 \\
\hline 2 & 0 & 1 & 1 & 0 \\
\hline 3 & 0 & 1 & 1 & 0 \\
\hline 4 & 0 & 1 & 1 & 1 \\
\hline 5 & 1 & 1 & 1 & 0 \\
\hline
\end{tabular}

Intepretasi tabel keputusan di atas adalah sebagai berikut:

a. Komponen Air Intake

Berdasarkan hasil keputusan, komponen Air Intake dilakukan program pemeliharaan: Bersihkan, Cek, dan Ganti

b. Komponen Filter HAF \& HMF

Berdasarkan hasil keputusan, komponen Filter HAF \& HMF dilakukan program pemeliharaan: Cek dan Ganti

c. Komponen OliMesin

Berdasarkan hasil keputusan, komponen Oli Mesin dilakukan program pemeliharaan: Cek dan Ganti

d. Komponen Air End

Berdasarkan hasil keputusan, komponen Air End dilakukan program pemeliharaan: Cek, Ganti, dan Perbaiki

e. Komponen Oil Separator

Berdasarkan hasil keputusan, komponen Oil Separator dilakukan program pemeliharaan: Bersihkan, Cek, dan Ganti

\section{Kesimpulan}

Hasil penelitian ini adalah suatu model keputusan program pemeliharaan dengan menggunakan pemrograman tujuan berdasarkan pertimbangan multikriteria AHP. Hasil pengembangan model matematika diaplikasikan ke dalam formula spreadsheet untuk menyelesaikan permasalahan keputusan pemeliharaan pada PT. X terhadap mesin yang dianggap kritis yaitu mesin kompresor dengan melibatkan lima buah komponen kritis yaitu: Air Intake, Filter HAF \& HMF, Oli Mesin, Air End (Services), dan Oil Filter. Model yang dikembangkan berhasil memilihkan program-program pemeliharaan yang optimal sesuai dengan target atau tujuan terhadap komponen kritis pada mesin yang dianggap kritis.

\section{Referensi}

[1] Saaty, T.L., 1990. Multicriteria Decision Making-The Analytical Hierarchy Process. RWS Publications, Pittsburgh.

[2] Triantaphyllou, E., Kovalerchuk, B., Mann, L., Knapp, J., 1997. Determining the most important criteria in maintenance decision making.Journal of Quality inMaintenance Engineering.

[3] Bevilacqua, M., Braglia, M., 2000. The analytic hierarchy process applied to maintenance strategy selection. Journal of Reliability Engineering and System Safety (70), 7183.

[4] Bertolini, M., Bevilacqua, M., 2005. A combined goal programming AHP approach to maintenance selection problem. Journal of Reliability Engineering and System Safety (91), 839848. 